\title{
Influenza immunization among Canadian health care personnel: a cross-sectional study
}

\author{
Sarah A. Buchan MSc, Jeffrey C. Kwong MD MSc
}

\section{Abstract}

Background: Influenza immunization coverage among Canadian health care personnel remains below national targets. Targeting this group is of particular importance given their elevated risk of influenza infection, role in transmission and influence on patients' immunization status. We examined influenza immunization coverage in health care personnel in Canada, reasons for not being immunized and the impact of "vaccinate-or-mask" influenza prevention policies.

Methods: In this national cross-sectional study, we pooled data from the 2007 to 2014 cycles of the Canadian Community Health Survey and restricted it to respondents who reported a health care occupation. Using bootstrapped survey weights, we examined immunization coverage by occupation and by presence of vaccinate-or-mask policies, and reasons for not being immunized. We used modified Poisson regression to estimate the prevalence ratio (PR) of influenza immunization for health care occupations compared with the general working population.

Results: For all survey cycles combined, 50\% of 18446 health care personnel reported receiving seasonal influenza immunization during the previous 12 months, although this varied by occupation type (range $4 \%-72 \%$ ). Compared with the general working population, family physicians and general practitioners were most likely to be immunized (PR 3.15, 95\% confidence interval [Cl] $2.76-$ 3.59), whereas chiropractors, midwives and practitioners of natural healing were least likely (PR $0.17,95 \% \mathrm{Cl} 0.10-0.30$ ). Among those who were not immunized, the most frequently cited reason was the belief that influenza immunization is unnecessary. Introduction of vaccinate-or-mask policies was associated with increased influenza immunization among health care personnel.

Interpretation: Health care personnel are more likely to be immunized against influenza than the general working population, but coverage remains suboptimal overall, and we observed wide variation by occupation type. More efforts are needed to target specific health care occupations with low immunization coverage.

\footnotetext{
$\checkmark$ easonal influenza causes substantial morbidity and mortality for high-risk groups such as older adults, young children and those with underlying medical conditions. ${ }^{1-3}$ These high-risk groups have frequent contact with the health care system and health care personnel., ${ }^{4,5}$ Health care personnel are at higher risk of influenza infection compared with people who work in non-health care settings ${ }^{6}$ and may be a source for influenza transmission in health care settings. ${ }^{7-9}$ Previous studies have suggested that there is an inverse relationship between health care personnel immunization and nosocomial infections. ${ }^{10}$ Furthermore, immunization beliefs and status of health care providers influence patient decisions about immunization. ${ }^{11}$

Canada's National Advisory Committee on Immunization (Public Health Agency of Canada) recommends annual seasonal influenza immunization for health care personnel as part of the standard of care for protecting patients, ${ }^{12}$ with a national target of $80 \%$ coverage for health care personnel
}

who have close contact with patients. ${ }^{13}$ The term "health care personnel" includes many diverse occupations, and studies estimating influenza immunization coverage among health care personnel have not commonly reported about specific occupations. ${ }^{14,15}$ Some studies in the United States have used large national surveys, but those results may not be generalizable to the Canadian context. ${ }^{16,17}$

Numerous organizations in the US have introduced mandatory influenza immunization policies for health care personnel, with subsequent notable increases in coverage. ${ }^{18,19}$ In

Competing interests: None declared.

This article has been peer reviewed.

Correspondence to: Jeffrey C Kwong, jeff.kwong@utoronto.ca CMAJ Open 2016. DOI:10.9778/cmajo.20160018 
recent years, several Canadian jurisdictions have implemented health care personnel "vaccinate-or-mask" influenza prevention policies, which require hospital-based health care personnel to either receive seasonal influenza immunization or wear a surgical mask during periods of influenza activity. Such policies were introduced in British Columbia and 1 of New Brunswick's 2 regional health networks (Horizon Health Network) in 2012-13, Saskatchewan in 2014-15 and selected hospitals across Ontario from $2012-13$ to $2014-15 .^{20,21}$

Our objectives for this study were to examine influenza immunization and the reasons for not being immunized, by health care occupation group and specific occupation. Additionally, we aimed to determine the impact of the introduction of vaccinate-or-mask influenza prevention policies on health care personnel influenza immunization coverage.

\section{Methods}

\section{Study population}

We used nationally representative data from the 2007 to 2014 cycles of the Canadian Community Health Survey (survey). ${ }^{22}$ Conducted annually by Statistics Canada since 2007 through telephone and in-person interviews, this cross-sectional survey contains questions related to health status, health care utilization and health determinants. ${ }^{22}$ Using a multistage stratified cluster design, each cycle includes a sample of about 65000 respondents aged 12 years and older. The survey excludes persons living on Aboriginal reserves, full-time members of the Canadian military, institutionalized persons and 2 remote health regions in Quebec (with all of these exclusions representing $<3 \%$ of the population). ${ }^{22}$

We restricted our study to respondents $15-75$ years of age who reported having a job during the week before being asked to respond to the survey. We assessed influenza immunization among those working in health care occupations. Response rates ranged from $65.6 \%$ to $77.6 \%$ across the survey cycles. ${ }^{23}$

\section{Sources of data}

We defined the dependent variable as self-reported influenza immunization within the past 12 months, determined through responses to the questions "Have you ever had a (seasonal) flu shot?" and "When did you have your last (seasonal) flu shot?". Respondents who reported receipt of their last flu shot during the preceding 12 months were considered immunized. These respondents were also asked "In which month did you have your last flu shot?." Those whose response matched the month of the survey date were then asked "Was that this year or last year?". We considered respondents who reported receipt of influenza vaccine during the same month as the survey date but in the preceding year as not immunized. Respondents who reported not receiving influenza immunization during the last 12 months were asked a series of questions related to their reasons for not being immunized.

To identify health care personnel, we used the National Occupation Classification for Statistics, established by Human Resources and Social Development Canada in partnership with Statistics Canada. ${ }^{24}$ Eligible respondents were asked about their specific occupation, which was coded and organized into a predefined hierarchy of 10 broad categories ( 1 of which comprises all health occupations) that are subdivided into health occupation groups and specific health occupations. We adapted this classification structure, making changes based on sample size and cohesiveness of the group (e.g., we combined chiropractors and practitioners of natural healing with midwives because both groups were too small on their own to produce sufficiently stable estimates to be reported and their coverage levels were similar).

We defined presence of a vaccinate-or-mask influenza prevention policy based on jurisdiction and influenza season (i.e., year). We considered British Columbia and the Horizon Health Network in New Brunswick to have this policy for 2012-13 and 2013-14. We included the survey health region that exclusively comprises Horizon Health Network and excluded Moncton because this city is split between Horizon Health Network and Vitalité Health Network. We also excluded Ontario from this analysis, because we could not align hospitals that introduced these policies with survey health regions.

To determine the presence of chronic medical conditions, respondents were asked whether they had been diagnosed by a health professional with asthma, chronic obstructive pulmonary disease, heart disease, stroke, diabetes or cancer, conditions for which influenza vaccines are recommended. ${ }^{12}$ The definitions for education, household income, smoking status, body mass index, immigration status, marital status, rural residence, self-reported health, and having a regular doctor were described previously. ${ }^{25,26} \mathrm{We}$ combined the 3 territories because of their small sample sizes.

\section{Statistical analysis}

We pooled individual-level responses from all survey cycles, with the final data set considered a sample from an average population observed over time. ${ }^{27}$ Using cross-tabulations, we estimated the overall proportion of health care personnel who reported seasonal influenza immunization during the previous year by various sociodemographic characteristics (i.e., age, sex, education, income and location), as well as by province and season. We also examined influenza immunization coverage by health occupation group and by specific occupation, looking at both whether the respondent had been immunized during the last 12 months and whether they had ever been immunized. Cross-tabulations were also used to examine the reasons provided by respondents who were not immunized and to compare jurisdictions that had introduced vaccinate-or-mask policies for health care personnel with those that had not.

We chose modified Poisson regression over logistic regression to estimate the prevalence of influenza immunization in specific health care occupations compared with other occupations outside of health care. Logistic regression analyses would have overestimated this relationship because of the high frequency of the outcome. ${ }^{28}$ Using modified Poisson regression also allows for the prevalence ratios to be interpreted as a relative risk. ${ }^{29} \mathrm{We}$ used the Hosmer-Lemeshow goodness-of-fit test forward model-building strategy to 
develop our multivariable model. ${ }^{30}$ We performed univariable regression analysis for all variables that were identified a priori to be of potential importance, and they were entered into the model based on their effect size. Variables that had a significant impact on the prevalence ratio for vaccination of health care personnel were kept in the model, with a verification step at the end to ensure no important variables were missed. Given its importance on influenza immunization uptake, age was forced into the model. After applying this model-building strategy, only age and sex remained in the model.

We used sampling weights to account for the unequal probability of selection in the sample and bootstrap survey weights to calculate variance estimates. We used normalized weights for the multivariable regression analysis. All tests were 2-sided and used a significance level of $p<0.05$. We used SAS statistical software (version 9.4, SAS Institute Inc.) for all analyses.

\section{Ethics approval}

This study was approved by the Ethics Review Board of Public Health Ontario.

\section{Results}

Our total sample included 249607 respondents (weighted $n=$ 16524003 ) aged 15-75 years who reported having a job during the previous week; of these, 18446 (weighted $n=$ 1130731 ) were classified as having a health care occupation. Most health care personnel were female, had attained high levels of education and had high household income (Table 1).

\section{Influenza immunization by occupation}

Overall, 50\% (95\% confidence interval [CI] 49\%-51\%) of health care personnel reported receiving seasonal influenza immunization during the past 12 months, and 77\% (95\% CI $76 \%-79 \%$ ) reported ever receiving immunization, compared with $21 \%$ (95\% CI 20\%-21\%) and 51\% (95\% CI 50\%-51\%), respectively, in the general working population. Immunization coverage in health care personnel varied between provinces (range 37\%-62\%) and influenza seasons (range 43\%-55\%).

We observed a wide range of coverage by health occupation group (range $4 \%-58 \%$ ) and by specific occupation (range $4 \%-72 \%$ ) (Table 2). The extent of variability was not consistent across health occupation groups: for example, coverage levels were similar between the 3 types of nurses $(53 \%$ for head nurses and supervisors, 58\% for registered nurses and $59 \%$ for licensed practical nurses) but ranged from 36\% to $61 \%$ among allied health professionals. Family physicians and general practitioners had the highest reported occupationspecific coverage $(72 \%, 95 \%$ CI $65 \%-79 \%)$, whereas chiropractors, midwives and practitioners of natural healing had the lowest $(4 \%, 95 \%$ CI $1 \%-7 \%)$.

In the multivariable analysis, healthcare personnel overall had significantly higher influenza immunization coverage than the general working population both before (prevalence ratio [PR] 2.43, 95\% CI 2.36-2.51) and after adjustment (PR $2.26,95 \%$ CI 2.19-2.34). This was also true for all health occupation groups except dental technicians and chiroprac- tors, midwives and practitioners of natural healing (Figure 1). Higher coverage was not observed for certain specific occupations (i.e., optometrists, veterinarians, veterinary technicians, dental hygienists and dental therapists, opticians, and those belonging to the other category of technical occupations in health care). Family physicians and general practitioners were most likely to receive influenza immunization (PR 3.15, 95\% CI 2.76-3.59), followed by licensed practical nurses (PR 2.69, 95\% CI 2.46-2.95), dieticians and nutritionists (PR 2.67, 95\% CI 2.23-3.20) and specialist physicians (PR 2.63, 95\% CI 2.29-3.02). In contrast, chiropractors, midwives and practitioners of natural healing were the least likely to receive influenza immunization (PR 0.17, 95\% CI 0.10-0.30).

\section{Reasons for not receiving influenza immunization}

Among those not immunized ( $n=8354$; weighted $n=$ 537674 ), the most frequently cited reason, consistent across all occupations, was believing influenza immunization to be unnecessary (all health care personnel $=67 \%$ ) (Table 3). Family physicians and general practitioners had the lowest percentage of citing this reason (52\%) among respondents, whereas chiropractors, midwives and practitioners of natural healing had the highest percentage (92\%). The other most frequently cited reasons included "not getting around to it" (14\%), "having a previous bad reaction" (10\%), and fear (5\%). This order was consistent across health occupation groups, except for nurses, for whom having a previous bad reaction was the second most frequently cited reason.

\section{Impact of vaccinate-or-mask policies on influenza immunization among health care personnel}

In areas where vaccinate-or-mask policies were implemented, influenza immunization among health care personnel increased from 52\% (95\% CI 49\%-56\%) before the $2012-$ 2013 influenza season to 68\% (95\% CI 62\%-74\%) after 2012-2013 compared with a change from 47\% (95\% CI $44 \%-49 \%)$ to $46 \%(95 \%$ CI $43 \%-50 \%)$ in areas that did not implement such policies (Figure 2).

\section{Interpretation}

\section{Main findings}

Immunization coverage among Canadian health care personnel remains below the national target, with large variations by specific occupation. Family physicians and general practitioners are most likely to receive influenza immunization, whereas chiropractors, midwives and practitioners of natural healing are least likely.

\section{Comparison with other studies}

Past studies of influenza immunizaton among health care personnel using Canadian Community Health Survey data considered health care personnel as a single entity and were based on industry classification rather than occupation type. Johansen and colleagues reported that $46 \%$ of people in health care industries in 2003 received their influenza vaccine. ${ }^{14}$ Gilmour and Hofmann examined uptake of H1N1 influenza vaccine in 


\section{OPEN}

Research

2010 and found that health care workers had significantly higher uptake than non-health care workers $(65.9 \% \mathrm{v}$. $34.8 \%) .{ }^{31}$ Some organization-specific studies have provided data on a limited number of subgroups but have focussed more on understanding attitudes and motivators of workers within these organizations. ${ }^{32,33}$ Saluja and colleagues noted variation in uptake among those who worked in emergency departments; however, they only reported on 4 health care worker groups. ${ }^{34}$

In the US, opt-in surveys of health care personnel have been conducted annually, with the most recent data reporting that $75.2 \%$ were immunized in $2013-14 .{ }^{35}$ This was highest for physicians (92.2\%) and for health care professionals whose employers required them to be immunized (97.8\%). ${ }^{35}$ The finding that physicians have the highest influenza immunization coverage among health care personnel is echoed in our study, as well as other national surveys. ${ }^{36}$ Additionally, our finding that influenza immunization coverage among health care personnel overall is suboptimal is also consistent with other research. ${ }^{36-40}$

We found that chiropractors, midwives and other practitioners of natural healing had the lowest uptake of influenza immunization. A previous survey of Ontario midwives also

\section{Table 1 (part 1 of 2): Selected demographic characteristics of the study population}

\begin{tabular}{|c|c|c|c|}
\hline Characteristic & $n$, unweighted & $n$, weighted (\%) & $\begin{array}{c}\text { Influenza immunization, } \\
\%(95 \% \mathrm{Cl})\end{array}$ \\
\hline All health care personnel & 18446 & 1130731 (100) & $50(49-51)$ \\
\hline \multicolumn{4}{|l|}{ Sex } \\
\hline Female & 15645 & $914069(80.8)$ & $50(49-51)$ \\
\hline Male & 2800 & $216662(19.2)$ & $51(48-54)$ \\
\hline \multicolumn{4}{|l|}{ Age, yr } \\
\hline $15-29$ & 3485 & $232521(20.6)$ & $45(43-48)$ \\
\hline $30-49$ & 8280 & $560815(49.6)$ & $48(46-50)$ \\
\hline $50-64$ & 6080 & 312206 (27.6) & $56(53-58)$ \\
\hline $65-75$ & 600 & $25188(2.2)$ & $70(65-76)$ \\
\hline \multicolumn{4}{|l|}{ Education } \\
\hline Some secondary & 365 & $16271(1.4)$ & $39(31-48)$ \\
\hline Secondary & 855 & $53360(4.7)$ & $47(40-53)$ \\
\hline Some postsecondary & 485 & $32473(2.9)$ & $38(31-45)$ \\
\hline Postsecondary & 16660 & $1024262(90.6)$ & $51(50-52)$ \\
\hline Not stated & 80 & $4365(0.4)$ & $56(39-72)$ \\
\hline \multicolumn{4}{|l|}{ Household income } \\
\hline Lowest* & 335 & $18363(1.6)$ & $42(33-51)$ \\
\hline Lower middle† & 1345 & $80223(7.1)$ & $46(40-52)$ \\
\hline Upper middleł & 4845 & $274579(24.3)$ & $45(43-48)$ \\
\hline Highest $\S$ & 11035 & $696155(61.6)$ & $53(51-54)$ \\
\hline Not stated/missing & 890 & $61411(5.4)$ & $51(45-57)$ \\
\hline \multicolumn{4}{|l|}{ Location } \\
\hline Urban & 13735 & $935286(82.7)$ & $51(49-52)$ \\
\hline Rural & 4710 & 195445 (17.3) & $48(46-51)$ \\
\hline \multicolumn{4}{|l|}{ Health occupation group } \\
\hline Diagnosing and treating professionals & 1405 & $110499(9.8)$ & $58(53-62)$ \\
\hline Chiropractors and midwives & 250 & $18852(1.7)$ & $4(1-7)^{\star \star}$ \\
\hline Allied health professionals & 1580 & $99048(8.8)$ & $48(44-53)$ \\
\hline Nurses & 6665 & $387740(34.3)$ & $57(55-60)$ \\
\hline Medical technologists and technicians & 1545 & $99112(8.8)$ & $43(39-47)$ \\
\hline Dental technicians & 450 & $31248(2.8)$ & $23(17-29)$ \\
\hline Other technical occupations in health care & 1020 & $58719(5.2)$ & $27(23-32)$ \\
\hline Assisting occupations in support of health services & 5535 & $325513(28.8)$ & $51(49-53)$ \\
\hline
\end{tabular}


Table 1 (part 2 of 2): Selected demographic characteristics of the study population

\begin{tabular}{|c|c|c|c|}
\hline Characteristic & $n$, unweighted & $n$, weighted (\%) & $\begin{array}{c}\text { Influenza immunization, } \\
\%(95 \% \mathrm{Cl})\end{array}$ \\
\hline \multicolumn{4}{|l|}{ Province/territory } \\
\hline Newfoundland and Labrador & 585 & $19891(1.8)$ & $37(32-43)$ \\
\hline Prince Edward Island & 315 & $5575(0.5)$ & $55(47-62)$ \\
\hline Nova Scotia & 840 & $39513(3.5)$ & $62(58-67)$ \\
\hline New Brunswick & 785 & $26715(2.4)$ & $50(45-54)$ \\
\hline Quebec & 3405 & $268993(23.8)$ & $40(37-43)$ \\
\hline Ontario & 5810 & $396944(35.1)$ & $52(50-54)$ \\
\hline Manitoba & 1325 & $49681(4.4)$ & $41(36-46)$ \\
\hline Saskatchewan & 1250 & $38231(3.4)$ & $59(55-63)$ \\
\hline Alberta & 1650 & $125895(11.1)$ & $56(52-60)$ \\
\hline British Columbia & 2095 & $157119(13.9)$ & $57(53-60)$ \\
\hline Territories combined & 380 & $2174(0.2)$ & $58(51-64)$ \\
\hline \multicolumn{4}{|l|}{ Influenza season } \\
\hline $2006-07$ & 1860 & $99821(8.8)$ & $52(48-55)$ \\
\hline 2007-08 & 2455 & $139235(12.3)$ & $51(48-55)$ \\
\hline 2008-09 & 2300 & $144191(12.8)$ & $53(50-57)$ \\
\hline $2009-10$ & 2320 & $143398(12.7)$ & $43(40-47)$ \\
\hline $2010-11$ & 2345 & $148604(13.1)$ & $51(47-54)$ \\
\hline 2011-12 & 2400 & $141030(12.5)$ & $47(43-50)$ \\
\hline $2012-13$ & 2415 & 155749 (13.8) & $49(46-53)$ \\
\hline $2013-14$ & 2345 & $158702(14.0)$ & $55(51-58)$ \\
\hline \multicolumn{4}{|c|}{ 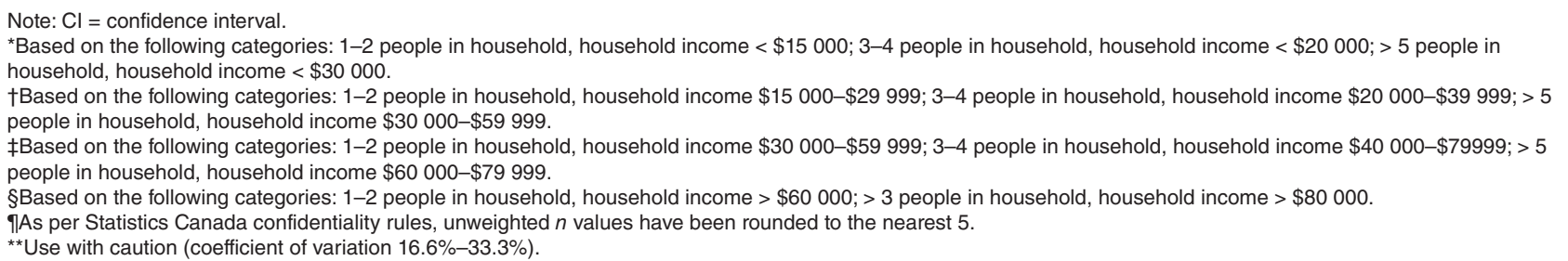 } \\
\hline
\end{tabular}

found that midwives were less likely to receive influenza immunization than other health care personnel. ${ }^{41}$ The use of alternative practitioners has become increasingly common in Canada. ${ }^{42,43}$ Like other health care personnel, they may have patients who are considered to be at high risk of serious complications from influenza infection, and, by not being immunized each year, they may be placing their patients at risk of serious morbidity and mortality from influenza infection. Given the burden of influenza during pregnancy and the effectiveness of influenza immunization in preventing influenza infection in both pregnant woman and their infants, ${ }^{44,45}$ and acknowledging the increasingly important role of midwives in pregnancy care, efforts are needed to promote influenza immunization within this group in particular.

Although some recent studies attempted to identify effective measures for promoting immunization of health care personnel in hospitals or primary care settings, results varied. ${ }^{32,46-50}$ Some research highlighted the beneficial impacts of enhanced education and the use of "champions" to increase coverage ${ }^{49,50}$ whereas others suggested the need for a larger paradigm shift to a culture of vaccine promotion. ${ }^{32,48,51}$ Despite this research at the organizational level, further studies focused on individual health care occupations, such as those identified here, and their specific concerns are needed; targeted strategies can then help bolster immunization coverage within the respective group..$^{52,53}$

\section{Limitations}

Our outcome measure, influenza immunization during the past 12 months, is self-reported and may be subject to reporting bias. Although past studies showed this outcome to be a valid measure of influenza immunization status, ${ }^{54,55}$ social desirability bias may have had a greater impact on health care personnel compared with the general population. Our study may also be limited in its ability to capture the full range of people who have patient contact but might not be classified as having a health care occupation. For example, we may have missed important groups, such as administrative or support 
Table 2: Influenza immunization among health care personnel, by occupation

\begin{tabular}{|c|c|c|c|c|}
\hline Occupation & $\begin{array}{l}n \text {, unweighted } \\
n=18446\end{array}$ & $\begin{array}{l}n, \text { weighted } \\
n=1130731\end{array}$ & $\begin{array}{l}\text { Flu shot in last } 12 \mathrm{mo} \\
\%(95 \% \mathrm{Cl})\end{array}$ & $\begin{array}{l}\text { Ever had flu shot } \\
\quad \%(95 \% \mathrm{Cl})\end{array}$ \\
\hline Diagnosing and treating professional & 1405 & 110499 & $58(53-62)$ & $80(76-84)$ \\
\hline Specialist physician & 380 & 31401 & $59(51-67)$ & $85(80-90)$ \\
\hline Family physician or general practitioner & 565 & 46902 & $72(65-79)$ & $86(80-93)$ \\
\hline Dentist & 205 & 17542 & $44(31-57)$ & $75(64-85)$ \\
\hline Optometrist & 85 & 4323 & $32(17-47) \dagger$ & $75(64-87)$ \\
\hline Veterinarian & 170 & 10331 & $20(11-29) \dagger$ & $46(32-59)$ \\
\hline Chiropractor, midwife or practitioner of natural healing & 250 & 18852 & $4(1-7) \dagger$ & $26(16-35) \dagger$ \\
\hline Allied health professional & 1580 & 99048 & $48(44-53)$ & $79(75-82)$ \\
\hline Pharmacist & 450 & 28134 & $50(43-58)$ & $79(71-86)$ \\
\hline Dietitian or nutritionist & 165 & 8338 & $61(50-72)$ & $84(75-92)$ \\
\hline Audiologist or speech language pathologist & 195 & 10857 & $36(26-47)$ & $78(68-88)$ \\
\hline Physiotherapist & 405 & 26938 & $44(36-51)$ & $73(66-80)$ \\
\hline Occupational therapist & 265 & 18399 & $51(39-62)$ & $83(76-89)$ \\
\hline Other professional occupation in therapy and assessment & 95 & 6382 & $55(40-70)$ & $86(77-95)$ \\
\hline Nurse & 6665 & 387740 & $57(55-60)$ & $84(83-86)$ \\
\hline Head nurse or supervisor & 485 & 29528 & $53(45-62)$ & $76(67-85)$ \\
\hline Registered nurse & 4970 & 295545 & $58(55-60)$ & $85(83-87)$ \\
\hline Licensed practical nurse & 1210 & 62667 & $59(54-64)$ & $84(81-88)$ \\
\hline Medical technologist or technician & 1545 & 99112 & $43(39-47)$ & $71(67-75)$ \\
\hline Medical laboratory technologist or pathologist's assistant & 420 & 26556 & $54(46-62)$ & $76(68-84)$ \\
\hline Medical laboratory technician & 295 & 20207 & $48(39-57)$ & $72(63-81)$ \\
\hline $\begin{array}{l}\text { Respiratory therapist, clinical perfusionist or cardiopulmonary } \\
\text { technologist }\end{array}$ & 125 & 9015 & $47(34-60)$ & $77(65-90)$ \\
\hline Medical radiation technologist & 335 & 19385 & $44(35-54)$ & $72(63-82)$ \\
\hline $\begin{array}{l}\text { Medical sonographer, cardiology technologist, } \\
\text { electroencephalographic or other diagnostic technologist, or other } \\
\text { medical technologist or technician }\end{array}$ & 130 & 8908 & $35(23-47) \dagger$ & $67(54-79)$ \\
\hline Veterinary technician & 235 & 15041 & $18(9-27) \dagger$ & $55(46-65)$ \\
\hline Dental technician & 450 & 31248 & $23(17-29)$ & $58(51-65)$ \\
\hline $\begin{array}{l}\text { Denturist or dental technologist, technician or laboratory bench } \\
\text { worker }\end{array}$ & 90 & 7680 & $33(20-47) \dagger$ & $56(41-71)$ \\
\hline Dental hygienist or dental therapist & 360 & 23568 & $19(13-26)$ & $59(51-67)$ \\
\hline Other technical occupation in health care & 1020 & 58719 & $27(23-32)$ & $60(55-65)$ \\
\hline Optician & 115 & 7928 & $15(6-25) \dagger$ & $39(25-53) \dagger$ \\
\hline Ambulance attendant or other paramedic occupation & 510 & 25678 & $46(38-53)$ & $83(78-88)$ \\
\hline Other & 390 & 25113 & $13(8-17) \dagger$ & $44(36-51)$ \\
\hline Assisting occupation in support of health services & 5535 & 325513 & $51(49-53)$ & $7876-80$ \\
\hline Dental assistant & 370 & 24747 & $32(24-39)$ & $66(59-74)$ \\
\hline Nurse aide, orderly and patient services associates & 4140 & 237232 & $56(53-59)$ & $82(80-84)$ \\
\hline Other & 1030 & 63534 & $38(33-43)$ & $69(64-73)$ \\
\hline
\end{tabular}

staff, who are employed in health care settings and have regular contact with patients. Additionally, the location of employment was unavailable; the importance of health care personnel immunization is expected to vary considerably by patient population and setting (e.g., intensive care unit versus community pharmacy or optical store). For the analysis examining the 
impact of vaccinate-or-mask policies, we may have misclassified health care personnel who work in 1 health authority in New Brunswick and live in the other, but this number was expected to be small. Furthermore, although New Brunswick and British Columbia implemented these policies for entire jurisdictions, several individual organizations also imple-
Occupation

Non-health care personnel

Health care personnel

Diagnosing and treating professionals

Specialist physicians

Family physicians and general practitioners

Dentists

Optometrists

Veterinarians

Chiropractors, midwives and practitioners of natural healing

Allied health professionals

Pharmacists

Dietitians and nutritionists

Audiologists and speech language pathologists

Physiotherapists

Occupational therapists

Other professional occupations in therapy and assessment

Nurses

Head nurses and supervisors

Registered nurses

Licensed practical nurses

Medical technologists and technicians

Medical lab technologists and pathologists' assistants

Medical laboratory technicians

Respiratory therapists, clinical perfusionists

and cardiopulmonary technologists

Medical radiation technologists

Medical sonographers, cardiology technologists,

electroencephalographic and other diagnostic technologists,

and other medical technologists and technicians

Veterinary technicians

Dental technicians

Denturists and dental technologists, technicians and lab bench workers

Dental hygienists and dental therapists

Other technical occupations in health care

Opticians

Ambulance attendants and other paramedical occupations Other

Assisting occupations in support of health services

Dental assistants

Nurse aides, orderlies and patient services associates

Other
Prevalence ratio* $(95 \% \mathrm{Cl})$

1.00 (ref)

$2.26(2.19-2.34)$

$2.54(2.33-2.78)$

$2.63(2.29-3.02)$

$3.15(2.76-3.59)$

$1.92(1.41-2.62)$

$1.54(0.98-2.41)$

0.93 (0.57-1.5)

$0.17(0.10-0.30)$

$2.23(2.04-2.45)$

$2.32(1.97-2.74)$

2.67 (2.23-3.2)

$1.7(1.27-2.27)$

1.98 (1.65-2.37)

$2.48(1.98-3.1)$

2.5 (1.86-3.35)

2.54 (2.43-2.65)

2.23 (1.89-2.63)

2.54 (2.41-2.67)

2.69 (2.46-2.95)

2.06 (1.86-2.27)

2.48 (2.09-2.95)

$2.32(1.86-2.89)$

2.13 (1.6-2.85)

$2.08(1.75-2.48)$

1.53 (1.07-2.19)

$1.01(0.63-1.63)$

$1.13(0.87-1.47)$

$1.57(1.01-2.42)$

$0.97(0.7-1.34)$

1.34 (1.13-1.59)

0.7 (0.41-1.19)

2.46 (2.06-2.94)

$0.58(0.41-0.82)$

$2.28(2.17-2.42)$

$1.54(1.2-1.96)$

$2.47(2.33-2.62)$

$1.82(1.59-2.08)$
Immunization Immunization $\longleftarrow$ less likely more likely $\longrightarrow$

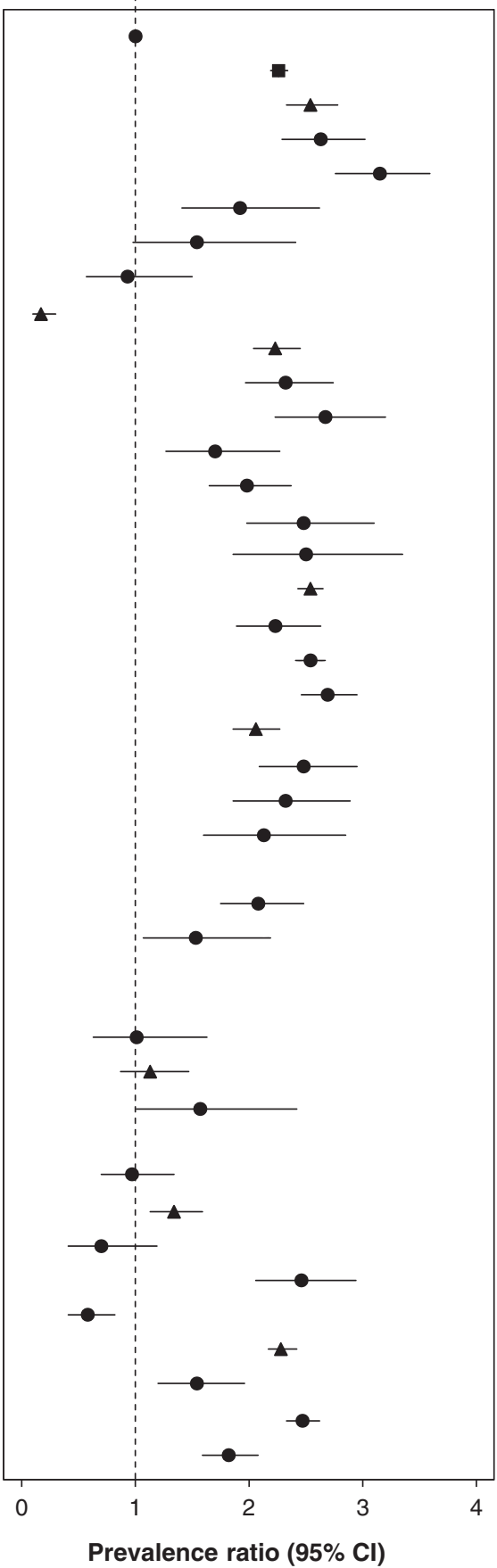

Figure 1: Prevalence ratios for influenza immunization (compared to the general working population) adjusted for age and sex, by health care occupation. Note: $\mathrm{Cl}=$ confidence interval. 
mented policies for their health care personnel, and we were unable to assess the impact of these organization-level policies with the available data. Finally, we were not able to look at trends over time for specific occupations because of sample size limitations.

\section{Conclusion}

Given the breadth of occupations represented by health care personnel, influenza immunization coverage should be measured using more specific categories. Our results suggest the need for targeted strategies to promote influenza immuniza-

Table 3: Nonimmunization for influenza among health care personnel, by occupation

\begin{tabular}{|c|c|c|c|}
\hline Occupation & $\begin{array}{l}n, \text { unweighted } \\
n=8534\end{array}$ & $\begin{array}{l}n, \text { weighted } \\
n=537674\end{array}$ & $\begin{array}{c}\text { Feels flu shot is } \\
\text { unnecessary, } \\
\%(95 \% \mathrm{Cl})\end{array}$ \\
\hline Diagnosing and treating professional & 585 & 44499 & $63(56-70)$ \\
\hline Specialist physician & 145 & 11275 & $57(45-70)$ \\
\hline Family physician or general practitioner & 125 & 12346 & $52(35-68)$ \\
\hline Dentist & 125 & 9679 & $72(59-84)$ \\
\hline Optometrist & 60 & 2924 & $54(36-71) \dagger$ \\
\hline Veterinarian & 130 & 8275 & $81(70-92)$ \\
\hline Chiropractor, midwife or practitioner of natural healing & 225 & 18101 & $92(87-97)$ \\
\hline Allied health professional & 760 & 48576 & $66(61-71)$ \\
\hline Pharmacist & 185 & 12443 & $63(52-74)$ \\
\hline Dietitian or nutritionist & 65 & 3186 & $87(77-97)$ \\
\hline Audiologist or speech language pathologist & 110 & 6662 & $57(43-71)$ \\
\hline Physiotherapist & 220 & 14642 & $73(65-82)$ \\
\hline Occupational therapist & 130 & 8989 & $61(49-74)$ \\
\hline Other professional occupation in therapy and assessment & 45 & 2654 & $54(32-77) \dagger$ \\
\hline Nurse & 2610 & 153313 & $63(59-66)$ \\
\hline Head nurse or supervisor & 185 & 12504 & $64(51-77)$ \\
\hline Registered nurse & 1915 & 116720 & $63(59-66)$ \\
\hline Licensed practical nurse & 510 & 24089 & $62(55-69)$ \\
\hline Medical technologist or technician & 815 & 55091 & $76(72-80)$ \\
\hline Medical laboratory technologist or pathologist's assistant & 180 & 11711 & $77(68-86)$ \\
\hline Medical laboratory technician & 155 & 10117 & $72(62-82)$ \\
\hline Respiratory therapist, clinical perfusionist or cardiopulmonary technologist & 60 & 4635 & $79(67-90)$ \\
\hline Medical radiation technologist & 150 & 10736 & $79(70-88)$ \\
\hline $\begin{array}{l}\text { Medical sonographer, cardiology technologist, electroencephalographic or } \\
\text { other diagnostic technologist, or other medical technologist or technician }\end{array}$ & 70 & 5651 & $75(62-88)$ \\
\hline Veterinary technician & 195 & 12241 & $75(64-86)$ \\
\hline Dental technician & 325 & 23189 & $63(54-72)$ \\
\hline Denturist or dental technologist, technician or laboratory bench worker & 60 & 4972 & $62(43-81) \dagger$ \\
\hline Dental hygienist or dental therapist & 265 & 18217 & $63(53-73)$ \\
\hline Other technical occupation in health care & 670 & 41155 & $76(71-81)$ \\
\hline Optician & 90 & 6438 & $78(65-90)$ \\
\hline Ambulance attendant or other paramedic occupation & 260 & 13318 & $69(59-78)$ \\
\hline Other & 320 & 21399 & $80(73-87)$ \\
\hline Assisting occupation in support of health services & 2540 & 153750 & $66(63-69)$ \\
\hline Dental assistant & 255 & 16714 & $71(62-81)$ \\
\hline Nurse aide, orderly and patient services associates & 1685 & 98569 & $65(61-69)$ \\
\hline Other & 600 & 38467 & $67(61-74)$ \\
\hline
\end{tabular}




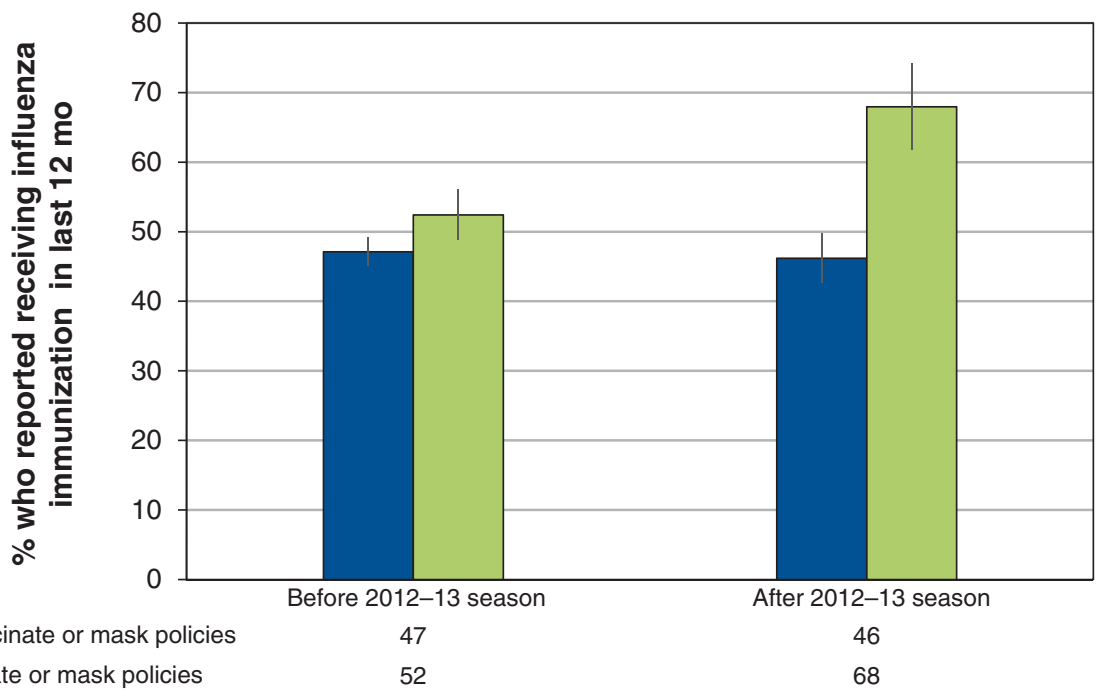

Figure 2: Influenza immunization, by presence of vaccinate-or-mask influenza prevention policies for health care personnel (excluding Moncton Health Region and the province of Ontario).

tion in groups with very low uptake and/or for whom provider protection is of critical importance to the patient population. Members of occupations with high coverage could serve as champions of influenza immunization for other health care personnel and patients.

\section{References}

1. Thompson WW, Shay DK, Weintraub E, et al. Mortality associated with influenza and respiratory syncytial virus in the United States. FAMA 2003; 289:179-86.

2. Harper SA, Bradley JS, Englund JA, et al. Seasonal influenza in adults and children - diagnosis, treatment, chemoprophylaxis, and institutional outbreak management: clinical practice guidelines of the Infectious Diseases Society of America. Clin Infect Dis 2009:48:1003-32.

3. Molinari NA, Ortega-Sanchez IR, Messonnier ML, et al. The annual impact of seasonal influenza in the US: measuring disease burden and costs. Vaccine 2007;25:5086-96.

4. Rosella LC, Fitzpatrick T, Wodchis WP, et al. High-cost health care users in Ontario, Canada: demographic, socio-economic, and health status characteristics. BMC Health Serv Res 2014;14:532.

5. Health care in Canada, 2011. A focus on seniors and aging. Ottawa: Canadian Institute for Health Information; 2011. Available: https://secure.cihi.ca/free_products/ HCIC_2011_seniors_report_en.pdf (accessed 2016 June 23).

6. Kuster SP, Shah PS, Coleman BL, et al. Incidence of influenza in healthy adults and healthcare workers: a systematic review and meta-analysis. PLoS One 2011;6:e26239.

7. Bryce E, Embree J, Evans G, et al. AMMI Canada position paper: 2012 Mandatory influenza immunization of health care workers. Can $\mathcal{7}$ Infect Dis Med Microbiol 2012;23:e93-5.

8. Eibach D, Casalegno JS, Bouscambert M, et al. Routes of transmission during a nosocomial influenza $\mathrm{A}(\mathrm{H} 3 \mathrm{~N} 2)$ outbreak among geriatric patients and healthcare workers. 7 Hosp Infect 2014;86:188-93.

9. Huttunen R, Syrjänen J. Healthcare workers as vectors of infectious diseases. Eur 7 Clin Microbiol Infect Dis 2014;33:1477-88.

10. Salgado CD, Giannetta ET, Hayden FG, et al. Preventing nosocomial influenza by improving the vaccine acceptance rate of clinicians. Infect Control Hosp Epidemiol 2004;25:923-8.

11. Frank E, Dresner Y, Shani M, et al. The association between physicians' and patients' preventive health practices. CMAJ 2013;185:649-53.

12. Statement on seasonal influenza vaccine for 2015-2016. Ottawa: Public Health
Agency of Canada; 2015. Available: www.phac-aspc.gc.ca/naci-ccni/flu -2015-grippe-eng.php (accessed 2016 June 23).

13. Vaccine coverage amongst adult Canadians: results from the 2012 adult National Immunization Coverage (aNIC) survey. Ottawa: Public Health Agency of Canada; 2014. Available: www.phac-aspc.gc.ca/im/nics-enva/vcac-cvac-eng.php (accessed 2016 June 23).

14. Johansen H, Sambell C, Zhao W. Flu shots: National and provincial/territorial trends. Health Rep 2006;17:43-8.

15. Brien S, Kwong JC, Charland KM, et al. Neighborhood determinants of 2009 pandemic A/H1N1 influenza vaccination in Montreal, Quebec, Canada. Am 7 Epidemiol 2012;176:897-908.

16. King WD, Woolhandler SJ, Brown AF, et al. Brief report: influenza vaccination and health care workers in the United States. 7 Gen Intern Med 2006;21:181-4.

17. Walker FJ, Singleton JA, Lu P, et al. Influenza vaccination of healthcare worker in the United States, 1989-2002. Infect Control Hosp Epidemiol 2006;27:257-65.

18. Black CL, Yue X, Ball SW, et al. Influenza vaccination coverage among health care personnel - United States, 2013-14 influenza season. MMWR Morb Mortal Wkly Rep 2014;63:805-11.

19. Miller BL, Ahmed F, Lindley MC, et al. Increases in vaccination coverage of healthcare personnel following institutional requirements for influenza vaccination: a national survey of U.S. hospitals. Vaccine 2011;29:9398-403.

20. Ksienski DS. Mandatory seasonal influenza vaccination or masking of British Columbia health care workers: year 1. Can 7 Public Health 2014;105:e312-6.

21. Vogel L. Vaccinate or mask pays off. CMA7 2015;187:19.

22. Canadian Community Health Survey - annual component (CCHS). Ottawa: Statistics Canada; 2014. Available: www23.statcan.gc.ca/imdb/p2SV. pl?Function=getSurvey\&SDDS=3226 (accessed 2016 June 23).

23. Canadian Community Health Survey - annual component. Ottawa: Statistics Canada; 2016. Available: www23.statcan.gc.ca/imdb/p2SV.pl? Function=get InstanceList\&Id=238854 (accessed 2016 June 23).

24. National Occupational Classification - Statistics (NOC-S). Ottawa: Statistics Canada; 2006. Available: www.statcan.gc.ca/pub/12-583-x/12-583-x2007001eng.pdf (accessed 2016 June 23).

25. Kwong JC, Sambell C, Johansen H, et al. The effect of universal influenza immunization on vaccination rates in Ontario. Health Rep 2006;17:31-40.

26. Quach S, Hamid JS, Pereira JA, et al. Influenza vaccination coverage across ethnic groups in Canada. CMA7 2012;184:1673-81.

27. Thomas S, Wannell B. Combining cycles of the Canadian Community Health Survey. Health Rep 2009;20:53-8.

28. Zhang J, Yu KF. What's the relative risk? A method of correcting the odds ratio in cohort studies of common outcomes. FAMA 1998;280:1690-1.

29. Zou G. A modified poisson regression approach to prospective studies with binary data. Am 7 Epidemiol 2004;159:702-6. 
30. Hosmer D, Lemeshow S. Model building strategies for logistic regression. In: Shewhart WA, Wilks SS, editors. Applied logistic regression. 2nd ed. New York: John Wiley; 2000.

31. Gilmour H, Hofmann N. H1N1 vaccination. Health Rep 2010;21:63-9.

32. Corace $\mathrm{K}$, Prematunge $\mathrm{C}, \mathrm{McC}$ arthy A, et al. Predicting influenza vaccination uptake among health care workers: What are the key motivators? Am 7 Infect Control 2013;41:679-84.

33. Mah MW, Hagen NA, Pauling-Shepard K, et al. Understanding influenza vaccination attitudes at a Canadian cancer center. Am 7 Infect Control 2005; 33:243-50.

34. Saluja I, Theakston KD, Kaczorowski J. Influenza vaccination rate among emergency department personnel: a survey of four teaching hospitals. CfEM 2005;7:17-21.

35. Centers for Disease Control and Prevention. Health personnel still not receiving flu vaccine. $7 A M A$ 2014;312:2203.

36. Guthmann JP, Fonteneau L, Ciotti C, et al. Vaccination coverage of health care personnel working in health care facilities in France: results of a national survey, 2009. Vaccine 2012;30:4648-54.

37. Murray SB, Skull SA. Poor health care worker vaccination coverage and knowledge of vaccination recommendations in a tertiary Australia hospital. Aust N Z 7 Public Health 2002;26:65-8.

38. Abu-Gharbieh E, Fahmy S, Rasool BA, et al. Influenza vaccination: healthcare workers attitude in three Middle East countries. Int 7 Med Sci 2010; $7: 319-25$.

39. Brunton C, Weir R, Jennings L. Knowledge and attitudes about influenza vaccination amongst general practitioners, practice nurses, and people aged 65 and over. NZMed $72004 ; 118:$ U1434.

40. Müller D, Nguyen-Van-Tam JS, Szucs TD. Influenza vaccination coverage rates in the UK: a comparison of two monitoring methods during the 20022003 and 2003-2004 seasons. Public Health 2006;120:1074-80.

41. Lee T, Saskin R, McArthur M, et al. Beliefs and practices of Ontario midwives about influenza immunization. Vaccine 2005;23:1574-8.

42. Wiles J, Rosenberg MW. 'Gentle caring experience'. Seeking alternative health care in Canada. Health Place 2001;7:209-24

43. Williams AM, Kitchen P, Eby J. Alternative health care consultations in Ontario, Canada: a geographic and socio-demographic analysis. BMC Complement Altern Med 2011;11:47.

44. Schanzer DL, Langley JM, Tam TWS. Influenza-attributed hospitalization rates among pregnant women in Canada 1994-2000. 7 Obstet Gynaecol Can 2007;29:622-9.

45. Madhi SA, Cutland CL, Kuwanda L, et al. Influenza vaccination of pregnant women and protection of their infants. NEngl 7 Med 2014;371:918-31.

46. Hollmeyer H, Hayden F, Mounts A, et al. Review: interventions to increase influenza vaccination among healthcare workers in hospitals. Influenza Other Respir Viruses 2013;7:604-21.

47. Lam PP, Chambers LW, MacDougall DMP, et al. Seasonal influenza vaccination campaigns for health care personnel: systematic review. CMA7 2010; 182:E542-8.

48. Prematunge C, Corace K, McCarthy A, et al. Qualitative motivators and barriers to pandemic vs. seasonal influenza vaccination among healthcare workers: a content analysis. Vaccine 2014;32:7128-34.
49. Abramson $\mathrm{ZH}$, Avni O, Levi O, et al. Randomized trial of a program to increase staff influenza vaccination in primary care clinics. Ann Fam Med 2010;8:293-8.

50. Slaunwhite JM, Smith SM, Fleming MT, et al. Increasing vaccination rates among health care workers using unit "champions" as a motivator. Can $\mathcal{F}$ Infect Control 2009;24:159-64.

51. Simeonsson K, Summers-Bean C, Connolly A. Influenza vaccination of healthcare workers: institutional strategies for improving rates. $N \mathrm{C} \mathrm{Med} 7$ 2004;65:323-9.

52. Harbarth S, Siegrist CA, Schira JC, et al. Influenza immunization: improving compliance of healthcare workers. Infect Control Hosp Epidemiol 1998;19:337-42.

53. Ishola DA, Permalloo N, Cordery RJ, et al. Midwives' influenza vaccine uptake and their views on vaccination of pregnant women. 7 Public Health (Oxf) 2013;35:570-7.

54. Mac Donald R, Baken L, Nelson A, et al. Validation of self-report of influenza and pneumococcal vaccination status in elderly outpatients. Am 7 Prev Med 1999;16:173-7.

55. Martin LM, Leff $M$, Calonge $N$, et al. Validation of self-reported chronic conditions and health services in a managed care population. Am 7 Prev Med 2000;18:215-8.

Affiliations: Dalla Lana School of Public Health (Buchan, Kwong), University of Toronto; Department of Family and Community Medicine (Kwong), University of Toronto; Institute for Clinical Evaluative Sciences (Kwong), Toronto, Ont.

Contributors: Both authors conceptualized and designed the study, interpreted the results, and drafted the manuscript. Sarah Buchan performed the analyses. Both authors reviewed the manuscript critically for intellectual content, approved the final version to be published and agreed to act as guarantors of the work.

Acknowledgements: Sarah Buchan was supported by a Canadian Immunization Research Network Trainee Award. Jeffrey Kwong was supported by a New Investigator Award from the Canadian Institutes of Health Research and a Clinician Scientist Award from the Department of Family and Community Medicine, University of Toronto. The authors thank David Haans and Joanna Jacob (Statistics Canada Research Data Centre, University of Toronto) for their support and guidance.

Supplemental information: For reviewer comments and the original submission of this manuscript, please see www.cmajopen.ca/content/4/3/ E479/suppl/DC1

ICES Disclaimer: This study was supported by the Institute for Clinical Evaluative Sciences, (ICES) which is funded by an annual grant from the Ontario Ministry of Health and Long-Term Care (MOHLTC). The opinions, results and conclusions reported in this article are those of the authors and are independent from the funding sources. No endorsement by ICES or the Ontario MOHLTC is intended or should be inferred. 